\title{
Baja California
}

National Cancer Institute

\section{Source}

National Cancer Institute. Baja California. NCI Thesaurus. Code C106163.

A state in Mexico comprising the northern half of the Baja California peninsula. Its capital is Mexicali. 